06

\title{
Исследование воздействия мощных потоков плазмы на образцы из пластин вольфрама с многослойной пленкой вольфрамовых наночастиц
}

() М.В. Горохов, В.М. Кожевин, Д.А. Явсин, А.В. Воронин, С.А. Гуревич

Физико-технический институт им. А.Ф. Иофффе РАН, Санкт-Петербург E-mail: mgorokhov@mail.ru

Поступило в Редакцию 10 ноября 2016 г.

Приведены результаты экспериментального исследования воздействия мощных потоков плазмы на образцы из пластин чистого вольфрама и вольфрама с многослойной пленкой вольфрамовых наночастиц. Облучение образцов проводилось на стенде плазменной пушки с плотностью мощности потока водородной плазмы до $35 \mathrm{GW} / \mathrm{m}^{2}$. Представлены результаты анализа образцов методом растровой электронной микроскопии. Показано, что пластины вольфрама, покрытые пленками из наночастиц, более устойчивы по отношению к появлению микротрещин, чем пластины чистого вольфрама.

DOI: 10.21883/PJTF.2017.07.44467.16566

Вольфрам рассматривается в качестве основного материала для термоядерных установок ИТЕР и ДЕМО, так как обладает рядом необходимых для этого свойств, в частности высокой температурой плавления, низким коэффициентом температурного расширения, хорошей теплопроводностью и низкой способностью удержания трития. Однако при высоких тепловых нагрузках происходит охрупчивание вольфрама, что делает его восприимчивым к образованию трещин вдоль границ зерен и затрудняет использование вольфрама в качестве функционального и конструкционного материала в условиях высоких температур.

В поиске решения проблемы образования трещин, обусловленных охрупчиванием вольфрама, исследуется поведение различных видов вольфрама под воздействием интенсивных тепловых нагрузок [1-4], ведутся разработки различных композитных материалов из вольфрама, 
в частности наноструктурированных композитов вольфрама с карбидом титана [5] и композитов, армированных вольфрамовыми волокнами [6]. Также большое внимание уделяется наноструктурам вольфрама с развитой волокнистой поверхностью типа W-fuzz [7,8]. Соответственно разработка новых видов вольфрамовых композитов и вольфрамовых пластин с наноструктурированной поверхностью представляется очень перспективным и важным направлением исследований.

Данная работа посвящена исследованию возможности повышения устойчивости пластин вольфрама к интенсивным тепловым нагрузкам за счет нанесения на их поверхность наноструктурированных пленок, состоящих из частиц вольфрама, формируемых методом лазерного электродиспергирования (ЛЭД), разработанным в ФТИ им. А.Ф. Иоффе [9]. Принципиальным отличием метода ЛЭД от других методов создания наноструктур является тот факт, что формирование наночастиц происходит не в процессе их синтеза из отдельных атомов, как это осуществляется в традиционных методиках, а является следствием каскадного деления микрокапель расплава металлов, заряженных до предела Рэлея, которое останавливается вследствие разряда капель, обусловленного полевой эмиссией электронов с их поверхности [9]. Нанокапли, образовавшиеся в финальной стадии деления микрокапель, застывают в полете, превращаясь в наночастицы. При этом важным для дальнейшего обсуждения полученных в работе экспериментальных результатов является тот факт, что образовавшиеся в процессе деления дочерние частицы, будучи заряженными, отталкиваются под действием кулоновских сил от материнских частиц, вследствие чего скорость наночастиц в момент их осаждения на подложку превышает $10^{4} \mathrm{~m} / \mathrm{s}$. Исследования показали, что наночастицы, формируемые методом лазерного электродиспергирования, являются аморфными и не коагулируют при соприкосновении. Также показано, что частицы имеют сферическую форму, их средний размер зависит только от материала мишени, и для вольфрама он составляет примерно $3 \mathrm{~nm}$. Соответственно формируемые многослойные пленки толщиной $100 \mathrm{~nm}$ состоят из более чем 30 слоев вольфрамовых наночастиц. Пленки наносились на вольфрамовые пластины толщиной $3 \mathrm{~mm}$ и размером $10 \times 10 \mathrm{~mm}^{2}$. Контроль толщины пленок осуществлялся с помощью профилометра Ambios Technology XP1.

Тестирование образцов проводилось на стенде плазменной пушки [10], позволяющем создавать на поверхности исследуемых вольфрамовых пластин импульсные тепловые нагрузки, подобные тем, которые возникают на диверторных пластинах термоядерных установок ИТЕР

Письма в ЖТФ, 2017, том 43, вып. 7 
и ДЕМО в случае реализации периферийной неустойчивости ELM (Edge-Localized Mode). Облучение образцов, находящихся при комнатной температуре, проводилось сериями из 15 импульсов гелиевой плазмы длительностью $15 \mu$ s каждый при плотностях потока энергии на поверхность образцов: 5, 10, 20 и $35 \mathrm{GW} / \mathrm{m}^{2}$. Для выявления роли покрытия образцов наноструктурой одновременно с исследуемым образцом облучался образец-спутник, не покрытый наноструктурой.

В процессе облучения образцов плазменным потоком также проводились измерения температуры их поверхности, которые осуществлялись с использованием быстродействующего двухцветного пирометра, разработанного IoffeLED Ltd [11].

Анализ структуры образцов проводился по результатам измерений морфологии образцов на сканирующем микроскопе CamScan S4-90 FE. Этот анализ показал, что первые признаки плавления поверхности наблюдаются на образце, покрытом наноструктурой при плотности мощности $10 \mathrm{GW} / \mathrm{m}^{2}$.

Существенно более явная перестройка структуры поверхности образцов обоих типов наблюдается при плотности мощности $20 \mathrm{GW} / \mathrm{m}^{2}$. На микрофотографии, представленной на рис. $1, a, b$, видно, что на поверхности образца объемного вольфрама сгладились следы механической обработки пластины, а на поверхности образца, покрытого наноструктурой, наблюдается процесс коалесценции наноструктуры вольфрама в сферические образования размером 200-300 nm. Наиболее интересные результаты были получены при самом интенсивном облучении образцов, т.е. при плотности потока мощности $35 \mathrm{GW} / \mathrm{m}^{2}$. Измерения температуры поверхности образцов при этой мощности показали, что она превосходит температуру плавления вольфрама и достигает величины $4000^{\circ} \mathrm{C}$. Измерения морфологии поверхности образцов после облучения указывают на существенное проплавление как образцов, покрытых наноструктурой, так и образцов без наноструктур.

В то же время при анализе структур на большом поле изображения, когда на поверхности образцов можно наблюдать наличие глубоких трещин, было обнаружено существенное различие их морфологии (рис. $1, c, d$ ). Так на образце, предварительно покрытом наноструктурой из наночастиц вольфрама, число характерных трещин значительно меньше, что может свидетельствовать о меньшей степени охрупчивания материала. При этом края трещин имеют четкий рельеф с характерным размером шероховатости около $100 \mathrm{~nm}$. Это, скорее всего, является 

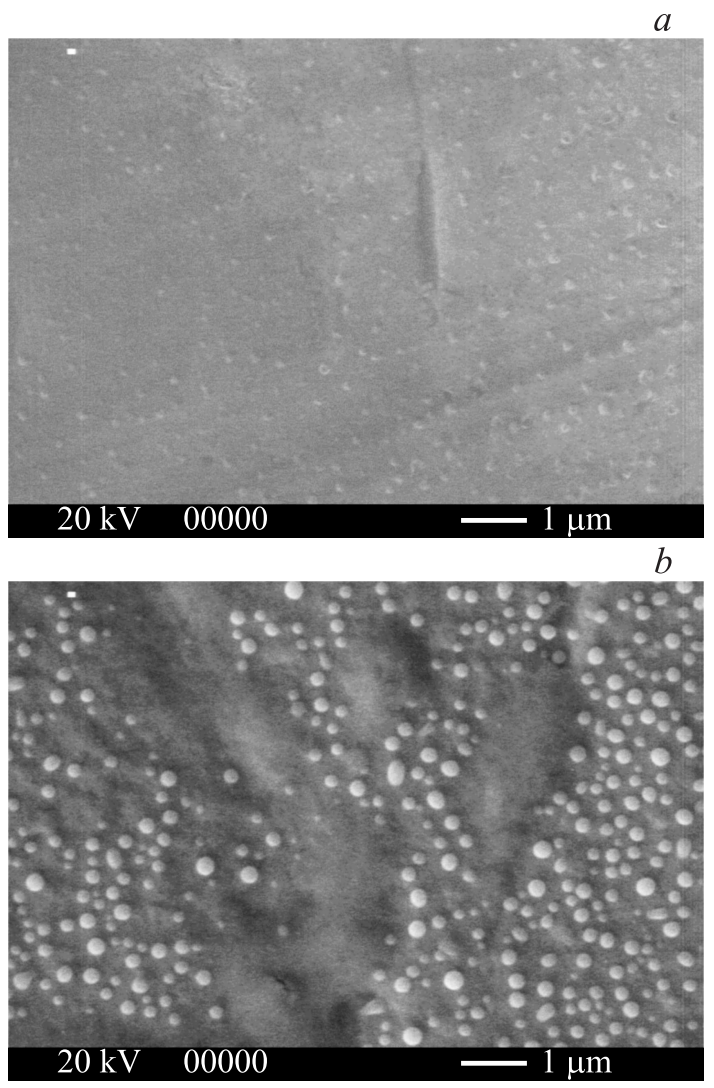

Рис. 1. Микрофотографии поверхности образца объемного вольфрама после облучения $(a, c)$ и образца $\mathrm{c} \mathrm{W}$-наноструктурой после облучения $(b, d)$. Плотность мощности $20 \mathrm{GW} / \mathrm{m}^{2}(a, b)$ и $35 \mathrm{GW} / \mathrm{m}^{2}(c, d)$.

следствием того, что трещины образуются на стадии остывания материала, т.е. растут из глубины образца [1].

Таким образом, проведенные экспериментальные исследования показали, что в образцах, покрытых пленкой вольфрамовых наночастиц, интенсивность образования микротрещин в вольфрамовых пластинах при высоких тепловых нагрузках оказывается ниже, чем в образцах без наночастиц.

Письма в ЖТФ, 2017, том 43, вып. 7 


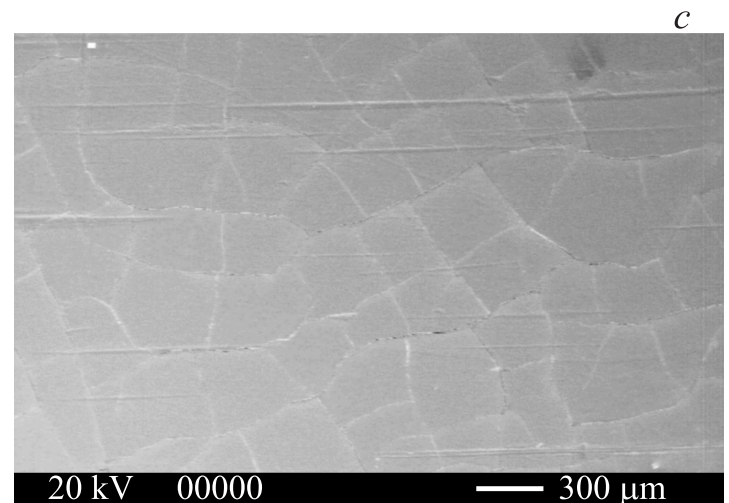

$d$

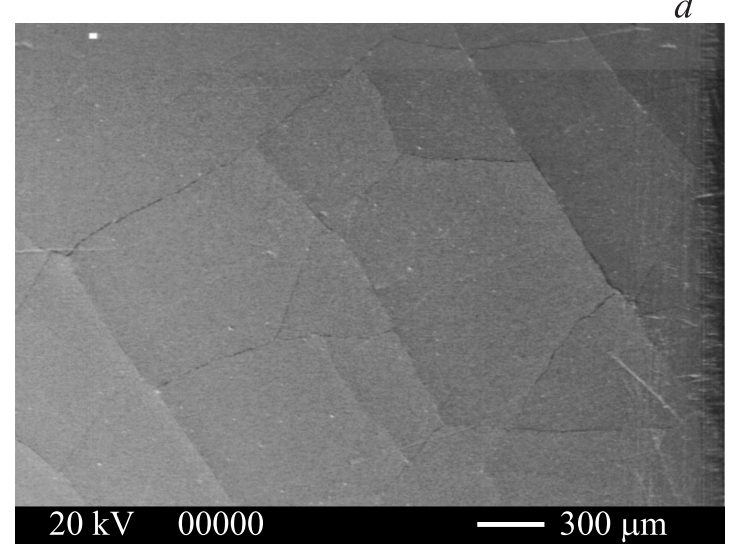

Рис. 1 (продолжение).

Отметим, что характер разрушения вольфрама зависит от содержания примесей (например, углерода), а также от размера зерен, их формы, плотности дислокаций [12]. Соответственно возможными причинами наблюдаемого эффекта могут быть влияние пленки, сформированной на поверхности образца, или модификация образца, обусловленная нанесением этой пленки. Первая из причин представляется маловероятной, поскольку наши оценки показывают, что за время импульса волна плавления распространяется внутрь образца на глубину

Письма в ЖТФ, 2017, том 43, вып. 7 


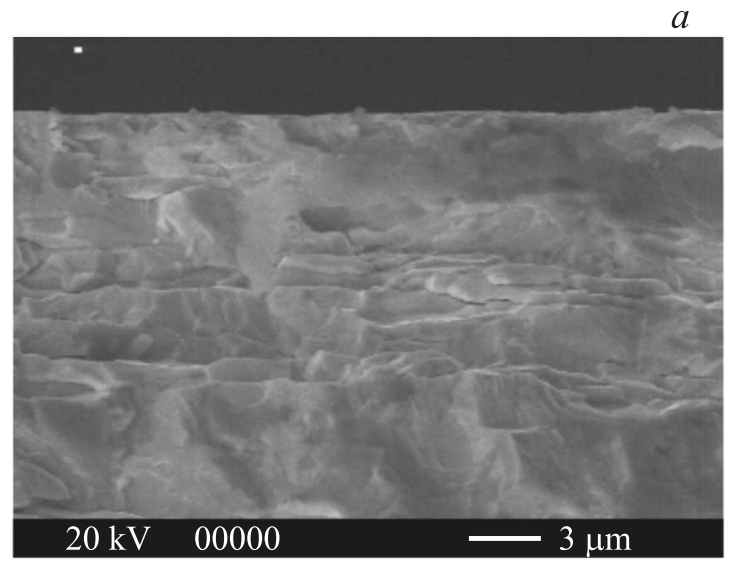

$b$

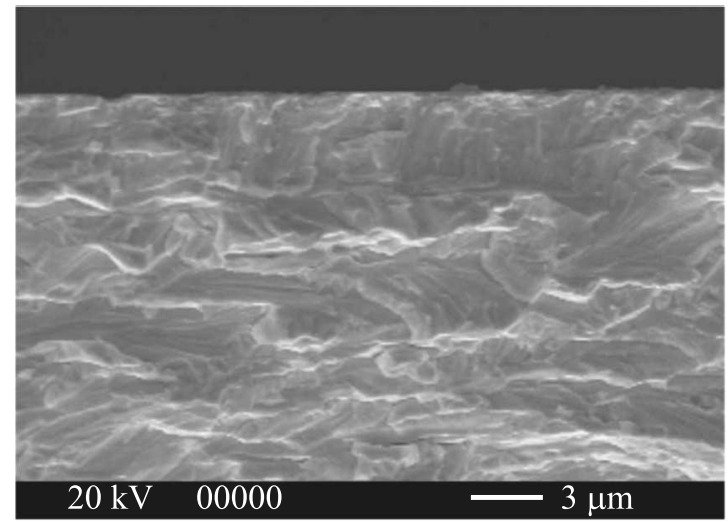

Рис. 2. Микрофотография поперечного сечения образца объемного вольфрама $(a)$ и образца с W-наноструктурой, нанесенной методом ЛЭД $(b)$.

около $10 \mu \mathrm{m}$, которая многократно превышает толщину нанопокрытия. Соответственно уже в процессе первого импульса наноструктура полностью расплавляется и сливается с образцом, и в дальнейшем она не может влиять на процесс образования трещин. Поэтому предполагаем, что обнаруженный эффект является следствием перестройки структуры самих образцов в момент нанесения на их поверхность покрытия

Письма в ЖТФ, 2017, том 43, вып. 7 
из наночастиц вольфрама. Такое изменение микроструктуры образца наблюдается на микрофотографиях поперечного сечения вольфрамовых пластин (рис. 2). На микрофотографии сечения образца без пленки наночастиц наблюдаются террасы (рис. $2, a$ ), а у образца, на который была нанесена пленка W-наночастиц, границы террас более размыты (рис. 2,b).

Перестройка структуры, скорее всего, обусловлена одной из основных особенностей метода ЛЭД, состоящей в необычно высокой скорости наночастиц при их осаждении на поверхность образца, которая превышает $10^{4} \mathrm{~m} / \mathrm{s}$. При такой скорости наночастиц образцу во время нанесения наноструктуры передается существенный импульс, под влиянием которого структура образца может изменяться и становиться более устойчивой к процессу формирования трещин.

Анализ экспериментальных данных показывает, что для типичных режимов нанесения вольфрамовых наноструктур плотность наночастиц, осаждаемых на подложку за один импульс, близка к $10^{14} \mathrm{~m}^{-2}$. Такой скорости осаждения во время импульса длительностью $30 \mathrm{~ns}$ соответствует поток наночастиц на поверхность, превышающий $10^{21} \mathrm{~m}^{-2} \cdot \mathrm{s}^{-1}$. Учитывая, что масса частиц равна $2 \cdot 10^{-21} \mathrm{~kg}$, получаем, что на поверхности образца во время импульса создается давление, превышающее $10^{5} \mathrm{~Pa}$. За время импульса звуковая волна распространяется внутрь образца на 100-200 m, что много меньше толщины образца, т. е. в приграничной области возникает волна сжатия с резким градиентом давления на фронте волны, оценочная величина которого равна $10^{10} \mathrm{~Pa} / \mathrm{m}$. В этом случае разница давлений между соседними зернами с характерным размером $1-10 \mu \mathrm{m}$ варьируется в диапазоне $10^{4}-10^{5} \mathrm{~Pa}$, что может привести к относительному сдвигу этих зерен. По окончании импульса поступление энергии в образец прекращается, и процесс проходит аналогично отражению ударной волны от свободной стенки, при котором вблизи стенки формируется волна разрежения. Таким образом, воздействие потока наночастиц, генерируемого в течение лазерного импульса, приводит к сжатию материала в приграничной области образца толщиной около $100 \mu \mathrm{m}$ в начале импульса и к его разрежению по окончании импульса. Поскольку для нанесения наноструктуры требуется около 30 тысяч импульсов, следующих с частотой $30 \mathrm{~Hz}$, то можно считать, что воздействие импульсного потока наночастиц на поверхность образца осуществляется в частотном режиме. Такое воздействие в принципе может привести к перестройке структуры образца, приводящей повышению его стойкости. 
Таким образом, показано, что процесс нанесения наноразмерных покрытий методом лазерного электродиспергирования может приводить к изменению структуры вольфрамовой подложки на глубину до нескольких микрон, что в свою очередь влияет на условия образования трещин в образце подложки при воздействии на него интенсивных тепловых нагрузок. В заключение отметим, что для окончательного подтверждения влияния импульсных потоков наночастиц на структуру образцов необходимо проведение большого объема дополнительных исследований.

Авторы благодарят за поддержку Министерство образования и науки РФ, субсидия 14.613.21.0014, уникальный идентификатор проекта RFMEFI61314X0014.

\section{Список литературы}

[1] Garkusha I.E., Makhlaj V.A., Aksenov N.N. et al. // J. Phys.: Conference Ser. 2015. V. 591. P. 012030 (1-12).

[2] Zhitlukhin A., Klimov N., Landman I. et al. // J. Nucl. Mater. 2007. V. 363-365. P. 301-307.

[3] Makhlaj V.A., Garkusha I.E., Aksenov N.N. et al. // Phys. Scr. 2014. V. 161. P. 014040.

[4] Анкудинов А.В., Воронин А.В., Гусев В.К. и др. // ЖТФ. 2014. Т. 84 . В. 3. C. $36-43$.

[5] Kurishita H., Arakawa H., Matsuo S. et al. // Mater. Trans. 2013. V. 54. N 4. P. 456- 465 .

[6] Riesch J., Han Y., Almanstötter J. et al. // Phys. Scr. 2016. V. 167. P. 014006.

[7] Nishijima D., Baldwin M.J. et al. // J. Nucl. Mater. 2011. V. 415. P. S96-S99.

[8] Wirtz M. et al. // Nucl. Mater. Energy. 2016. V. 9. P. 177-180.

[9] Kozhevin V.M., Yavsin D.A. et al. // J. Vac. Sci. Technol. B. 2000. V. 18. P. 1402 1405.

[10] Voronin A.V., Gusev V.K., Petrov Y.V. et al. // Dense plasma source development and jet injection in Globus-M. Nukleonika, 2008. V. 53. N 3. P. 103-109.

[11] Воронин А.В., Александров А.Е., Бер Б.Я. // ЖТФ. 2016. Т. 86. В. 3. С. 51-57.

[12] Rieth M. et al. // J. Nucl. Mater. 2013. V. 432. P. 482-500.

Письма в ЖТФ, 2017, том 43, вып. 7 